\title{
Strengthening the Scientific Basis of Ecosystem Collapse Risk Assessments
}

\author{
Adrian C. Newton
}

Citation: Newton, A.C.

Strengthening the Scientific Basis of Ecosystem Collapse Risk Assessments. Land 2021, 10, 1252. https://doi.org/10.3390/land10111252

Academic Editors: Patrick J. Comer and Reed F. Noss

Received: 25 October 2021

Accepted: 12 November 2021

Published: 16 November 2021

Publisher's Note: MDPI stays neutral with regard to jurisdictional claims in published maps and institutional affiliations.

Copyright: (C) 2021 by the author. Licensee MDPI, Basel, Switzerland. This article is an open access article distributed under the terms and conditions of the Creative Commons Attribution (CC BY) license (https:// creativecommons.org/licenses/by/ $4.0 /)$.
Centre for Ecology, Environment and Sustainability, Faculty of Science and Technology, Bournemouth University, Poole BH12 5BB, UK; anewton@bournemouth.ac.uk

\begin{abstract}
Progress is being made in assessing the conservation status of ecosystems, notably through initiatives such as the IUCN Red List of Ecosystems (RLE) and the NatureServe Conservation Status Assessment (NCS). Both of these approaches consider conservation status in terms of the risk of ecosystem collapse. However, the scientific understanding of ecosystem collapse is still at a relatively early stage. Consequently, concerns have been raised regarding the scientific basis of ecosystem conservation assessments focusing on collapse risk. Here I explore how these concerns might potentially be addressed by considering how the concept is defined, and by briefly reviewing the theoretical basis of ecosystem collapse. I then examine the implications of recent research results for the design of ecosystem collapse risk assessments, and the challenges identified in those assessments conducted to date. Recommendations are made regarding how collapse risk assessments might be strengthened based on current scientific understanding, and how this understanding could be improved by further research. In addition, I examine the potential implications for conservation policy and practice if the scientific basis of collapse risk assessments is not strengthened in this way.
\end{abstract}

Keywords: ecosystem collapse; biodiversity loss; conservation; environmental management; ecosystem degradation

\section{Introduction}

Approaches for identifying taxonomic groups that are threatened with extinction are now well established. Using methods developed by the IUCN Red List of Threatened Species (RLTS), major global assessments of extinction risk have been conducted for several different groups of species, including mammals, birds, reptiles, amphibians and most recently trees [1,2]. Conversely, efforts to identify threatened ecosystems are at a much earlier stage of development. Although a number of previous initiatives have sought to prioritise ecosystems for conservation, especially at the national scale, it is only recently that attempts have been made to develop standardised approaches for evaluating risk, comparable to the way in which the RLTS assesses the extinction risk of species [3]. Notable examples include the IUCN Red List of Ecosystems (RLE) [4-8] and NatureServe's Conservation Status (NCS) ranking system $[9,10]$. Both of these approaches are designed to assess the collapse risk of ecosystems. As a partner of the IUCN Red List, NatureServe has latterly sought to align its ecosystem assessment approach with that of the RLE, which accounts for the common reference to ecosystem collapse among their assessment categories $[4,11]$. While the NCS has undertaken ecosystem assessments throughout the Americas and the Caribbean, the RLE has so far completed around 70 assessments distributed throughout the world, and is aiming for complete global coverage in the near future.

Both the RLE and the NCS have already had a significant impact on conservation policy and practice. The RLE is being used to inform environmental legislation, land-use planning and protected area management [12], as well as the development of conservation strategies [13], restoration priorities [14] and indicators to support policy implementation [15]. Results are also informing global environmental assessments, such as the Global Biodiversity Outlook) [16] and the Global Environment Outlook (GEO-6 [17]), as well as 
their associated policy processes [18]. Similarly, the NatureServe assessment system has been used extensively throughout the United States and Canada, as well as in a number of other countries, to support conservation decision-making. Assessments have informed the identification of priorities for conservation actions and management interventions, as well as the development of indicators for environmental monitoring $[19,20]$.

Despite these impressive achievements, concerns have been raised regarding the scientific basis of current approaches to assessing ecosystem collapse risk. Specifically, Boitani et al. [21] provided a detailed critical evaluation of the RLE as it was being developed. Criticisms voiced by these authors included the following: (i) there is no consistent means to classify ecosystems for assessing conservation status; (ii) there are technical difficulties with the proposed concept of ecosystem collapse, which is not analogous to species extinction; (iii) the criteria and thresholds proposed lack a robust scientific basis. Boitani et al. [21] concluded that the RLE has "fundamental weaknesses as well as practical difficulties" that "will risk misinterpretations, ambiguities, and approximations", which could "lead to poorly based conservation priorities and completely discredit the RLE process". Significant efforts have subsequently been made to address some of these concerns. For example, a new Global Ecosystem Typology is being developed by the IUCN, which classifies ecosystems based on their functional characteristics and species composition [22]. This should help provide the consistent approach to ecosystem classification that Boitani et al. called for. Further responses to the criticisms levied are provided by Keith et al. [8], who defend the threshold values associated with each RLE criterion; these values are used to assign an ecosystem to a particular threat category. According to Keith et al. [8], practical utility needs to be the primary consideration for setting these threshold values, rather than the theoretical justification demanded by Boitani et al. [21]. However, the difficulties associated with the concept of ecosystem collapse raised by Boitani et al. [21] were not fully addressed by Keith et al. [8].

Although the term 'ecosystem collapse' has featured in the scientific literature since the 1980 's, it is only during the last decade that the issue has become a significant focus of research, illustrated by a rapid increase in the number of scientific publications on the topic [23-26]. This reflects increasing concern about the scale, magnitude and rate of the changes that are occurring in many of the world's ecosystems, associated with intensifying climate change and other impacts of human activity on the biosphere. Development of the RLE has itself stimulated scientific interest in ecosystem collapse, and the term now appears frequently in the international media, partly owing to its use by high-profile environmentalists $[25,27]$. Yet the scientific basis of ecosystem collapse has received relatively little attention from researchers to date. Recently I provided an overview of the theoretical ideas that are relevant to understanding the phenomenon, together with an evaluation of available empirical evidence drawn both from prehistory and the contemporary world [25]. Here I explore the implications of this current understanding for the evaluation of collapse risk, specifically in relation to the design and implementation of the RLE and NCS. Unlike Boitani et al. [21], I fully support the call for conservation assessments of ecosystems; there is indeed an urgent need to conserve interactions between species, ecological processes, ecosystem functions and entire communities, as well as individual species $[5,7,8]$. However, the societal value of conservation assessments such as the RLE ultimately depends upon their scientific credibility. If there are opportunities to strengthen the scientific basis of ecosystem assessments, then these should be explored. Here I identify a series of such opportunities, in the hope that they will inform future development of ecosystem assessments such as the RLE and NCS, and contribute to their improvement. The ideas presented below are not intended as definitive recommendations, but rather they are suggestions that are tentatively offered to stimulate further reflection and debate.

\section{Change the Endpoint}

Both the RLE and NCS include "Collapsed" as an assessment category, to signify the endpoint of a process of ecosystem degradation and loss. Based on this, the RLE describes 
itself as an assessment of "collapse risk". Whether or not this is appropriate depends on how the term "ecosystem collapse" is defined. The RLE has helpfully provided a formal definition of collapse, which is applied in the assessment process (Table 1). However, this does not constitute "collapse" as most people would understand it. This is because the word "collapse" signifies abrupt change, a point that is not made explicit in the RLE definition. To illustrate this, I here provide definitions of the word "collapse" obtained from a series of on-line dictionaries. In every case, the definition of collapse explicitly refers to "abrupt" or "sudden" change (Table 2). Yet the RLE definition does not; indeed, the scientific foundations and supporting guidelines of the RLE explicitly state that transitions to ecosystem collapse may be gradual $[4,7]$.

Table 1. Different definitions of ecosystem collapse available in the scientific literature. The formal definition employed by the RLE is that of Bland et al. [4].

\begin{tabular}{lc}
\hline \multicolumn{1}{c}{ Definition } & Reference \\
\hline A transformation of identity, a loss of defining features, and a replacement by a different ecosystem type. \\
An ecosystem is collapsed when all occurrences lose defining biotic or abiotic features, no longer sustain \\
the characteristic native biota and have moved outside their natural range of spatial and temporal \\
variability in composition, structure and/or function.
\end{tabular}

Table 2. Definitions of the word "collapse", obtained from on-line dictionaries.

\begin{tabular}{|c|c|}
\hline Definition & Source \\
\hline To fall down suddenly because of pressure or having no strength or support & Cambridge Dictionary ${ }^{1}$ \\
\hline To fall or cave in; crumble suddenly & Dictionary.com ${ }^{2}$ \\
\hline To fall or shrink together abruptly and completely & Merriam-Webster ${ }^{3}$ \\
\hline If a building or other structure collapses, it falls down very suddenly & Collins Dictionary ${ }^{4}$ \\
\hline Fall down suddenly & Macmillan Dictionary ${ }^{5}$ \\
\hline Suddenly fall down or give way & Oxford English Dictionary ${ }^{6}$ \\
\hline To fall down or inward suddenly; cave in & The Free Dictionary ${ }^{7}$ \\
\hline If a building, wall etc. collapses, it falls down suddenly, usually because it is weak or damaged & Longman $^{8}$ \\
\hline
\end{tabular}

Definition of the term 'ecosystem collapse' should therefore include explicit reference to 'abrupt' or 'sudden' change, as proposed in the definition given by Newton et al. [28] (Table 1). This suggested definition differs from that developed by the RLE in a number of additional ways: (i) it does not require replacement by a different ecosystem type; it could just refer to a loss of defining features, without necessarily involving a transformation of identity; (ii) it could be applied to individual occurrences of an ecosystem, such as those located within a particular area, and is therefore more applicable for use at a local scale; (iii) it explicitly requires that collapse is persistent, precluding the possibility of recovery within decadal timescales. This reflects the fact that ecosystem collapse can often be attributed to a failure to recover from perturbations, owing to ongoing chronic disturbance [25]. 
The reasons why ecosystem collapse was selected by the RLE as a term to describe an endpoint is not explained in the supporting literature; interestingly it does not appear in the earliest publications proposing the assessment [3,29]. There are potential advantages in employing the term, as it is attractive to the international media and conservation advocates. However, this popularity arises because it plays on a fear that ecosystems might suddenly decline, which is implied by the word "collapse". It has long been established that the international media are increasingly using fear to build interest in news reports [30]. However it has also been shown that creating fear through the use of threatening messages is not necessarily the best way of generating support for conservation [31]. Furthermore, use of the term "collapse" to describe ecosystems that are not declining rapidly is arguably deceptive. For these reasons, the RLE should consider using an alternative term to describe both the process of ecosystem decline and its endpoint, such as a process of transformation leading to an ecosystem that is completely transformed. This terminology would be consistent with the definition of the endpoint developed by the RLE (Table 1).

\section{Strengthen Links with Theory}

The scientific rigour of any assessment process ultimately relies on its relationship with underlying theory. The RLTS took particular care to identify a clear theoretical basis for its assessment criteria and associated classification thresholds; these were based on theories of population dynamics and extinction, as explored through models of Population Viability Analysis [32]. The RLE has similarly attempted to base its design on relevant ecological theory. A range of theoretical ideas were cited in development of the RLE [4,7], some of which are listed here (Table 3). A further list of theories relevant to ecosystem collapse examined by Newton [25] is provided for comparison.

Table 3. Examples of theoretical ideas relevant to an understanding of ecosystem collapse. Note that some of the ideas cited by the RLE by Bland et al. [4] were not explicitly referred to by name, but through citation of supporting references. Moreover, Newton [25] did not consider theoretical ideas relating to individual species or species richness (e.g., metapopulation theory or island biogeography theory).

\begin{tabular}{cc}
\hline Theoretical Ideas Considered by the RLE (Bland et al. [4]) & Theoretical Ideas Considered by Newton [25] \\
\hline Diversity-ecosystem function relationships & Critical loads \\
Dynamical systems theory & Disturbance theory \\
Island biogeography theory & Dynamical systems theory \\
Metapopulation theory & Ecosystem recovery \\
Niche theory & Ecosystem resilience \\
Population Viability Analysis, population dynamics theory & Food webs, ecological networks and extinction cascades \\
Small population paradigm & Planetary boundaries \\
Species accumulation curves/species-area relationships & State-and-transition models \\
State-and-transition models & Succession \\
Trophic cascades & Trophic cascades \\
\hline
\end{tabular}

Although no single theory has been developed that provides a comprehensive understanding of ecosystem collapse, these lists (Table 3) illustrate that many theoretical ideas drawn from different areas of ecology can potentially contribute to this understanding. These ideas have been represented in a number of different ways; while some theories are mathematical, others are largely conceptual or are derived from empirical data. This supports a pluralist view of the role of theory in ecology; while theories represented mathematically may be less ambiguous and more amenable to rigorous empirical testing, conceptual theories or those based on empirical patterns can also be very valuable [33-37]. Comparison of the lists presented on Table 3 shows that some theoretical ideas that are important to understanding ecosystem collapse, such as succession theory, disturbance theory and critical loads, were not explicitly considered during development of the RLE. However, neither of these lists is complete. Additional ideas that are relevant to understanding 
ecosystem collapse include metacommunity theory [38], landscape ecology theory [39], hierarchy theory [40] and complexity theory [41].

The theory that has most often been associated with ecosystem collapse is dynamical systems theory, which includes a range of connected ideas including bifurcation theory, catastrophe theory, critical transitions, alternative stable states, resilience, tipping points and regime shifts [42-45]. Some authors have explicitly linked ecosystem collapse to these theoretical ideas (e.g., [46]), including the RLE in their conceptualisation of collapse as a transition between ecosystem states $[4,8]$. Different ecosystem states can be readily observed in nature, but these do not always correspond to the alternative stable states postulated by theory [25,43]. In fact, this suggestion has been challenged in a variety of different ecosystem types, including freshwater ecosystems [47], savannas [48] and coral reefs [49]. Partly this is because key assumptions of the theory are often not met in field situations (e.g., [49,50]). Furthermore, dynamical system theory is not applicable to situations involving complete and direct ecosystem conversion, which currently comprises the principal form of ecosystem collapse [28]. This highlights the risk of relating ecosystem collapse to a single mechanism, and the need for care when invoking any theoretical idea.

In their critical evaluation of the RLE, Boitani et al. [21] identified the lack of a strong linkage between ecological theory and the RLE assessment criteria or their associated thresholds. For example, Boitani et al. [21] maintain that there is little scientific basis for applying theoretical ideas relating to declines of species (e.g., species-area models or the small population paradigm) to the collapse of ecosystems, as suggested for Criterion A (reduction in geographic distribution). Similarly, these authors suggested that the quantitative thresholds for Criterion B (restricted geographic distribution) are not linked to collapse by ecological theory in a way that can be applied consistently at all scales. In fact, the lack of a close link between theory and the thresholds of the RLE is recognised by the authors of the RLE itself [4]. For example Keith et al. [7] state: “.. in the absence of a clear theoretical foundation for setting particular thresholds ..., we set threshold values at relatively even intervals for current and future declines." Boitani et al. [21] point out that this approach assumes that a linear relationship exists between probability of collapse and values of the criteria, which is contradicted by some evidence (e.g., [51]).

To provide a stronger scientific basis for the criteria and thresholds used in collapse risk assessments, Boitani et al. [21] suggest that a general theory is needed that links ecosystem reduction (of area, components, and functions) to collapse, which is applicable at all scales and to all ecological systems. How might such a general theory of ecosystem collapse be developed? One approach might be to integrate different elements drawn from existing theories (Table 3), for example by identifying a set of propositions based on the results of previous research. Identification of propositions based on theoretical ideas can help summarise existing knowledge, while also providing a basis for the development of further questions or hypotheses; they can also be viewed as components of a theory [37,52]. As a first step towards this goal, some tentative propositions are presented on Table 4. These are not intended to be definitive, but are provided to stimulate further debate and development, while also providing a basis for future research. Each of these propositions is based on ecological theory, and is supported by empirical evidence [25]. Some other propositions were not supported by such evidence. For example, there appears to be no consistent relationship between species richness and likelihood of collapse [25], which reflects the broader lack of consensus regarding the relationship between the stability and diversity of ecological systems $[53,54]$. 
Table 4. Selected propositions relating to ecosystem collapse and recovery, derived from ecological theory and supported by empirical data. Adapted from Newton [25].

\begin{tabular}{|c|c|}
\hline No. & Proposition \\
\hline 1 & $\begin{array}{l}\text { Any ecosystem can potentially collapse, if subjected to disturbance of an appropriate type and occurring at sufficient } \\
\text { frequency, extent, intensity or duration, and especially if the disturbance is novel. }\end{array}$ \\
\hline 2 & $\begin{array}{l}\text { Ecosystem collapse is most often caused by extrinsic factors (i.e., disturbance), sometimes in combination with intrinsic } \\
\text { factors (e.g., interactions between organisms). }\end{array}$ \\
\hline 3 & Ecosystems subjected to multiple types of disturbance are more likely to collapse, especially if these disturbances interact. \\
\hline 4 & $\begin{array}{l}\text { Collapse is most commonly driven by chronic ("press") disturbances, although acute ("pulse") disturbances can also } \\
\text { be influential. }\end{array}$ \\
\hline 5 & $\begin{array}{l}\text { Many ecosystems can exist in more than one state; transitions between these states can form part of natural dynamics. } \\
\text { However, transitions that are normally transient can become persistent as a result of chronic disturbance. }\end{array}$ \\
\hline 6 & $\begin{array}{l}\text { A persistent ecosystem transition, or collapse, can arise when ecological recovery is impeded. This can occur if there are } \\
\text { stabilising feedback processes that maintain an ecosystem in a degraded state, if there is chronic disturbance, or when the } \\
\text { processes of ecological recovery fail. Understanding these reasons for lack of recovery is key to understanding collapse. }\end{array}$ \\
\hline 7 & $\begin{array}{l}\text { Collapse can be caused by breakdown of the stabilising feedback mechanisms maintaining an ecosystem state, or by } \\
\text { feedbacks in the internal ecological processes of an ecosystem driving a system to a different state. As a result of these } \\
\text { feedbacks, major ecological shifts can result from minor perturbations. Such shifts can occur when extrinsic factors reach a } \\
\text { critical value. }\end{array}$ \\
\hline 8 & $\begin{array}{l}\text { Ecosystem collapse is more likely if disturbance events cause the loss of: (a) generalist species, (b) top predators and/or } \\
\text { trophically unique species, (c) those at the base of food chains, and especially (d) those that are highly connected to other } \\
\text { species through ecological networks. Loss of such species can cause many secondary extinctions, which can lead to collapse } \\
\text { of ecological networks. }\end{array}$ \\
\hline 9 & $\begin{array}{l}\text { Functional and structural change in an ecosystem undergoing collapse may be unrelated to loss of taxonomic diversity, but } \\
\text { may be affected by loss of species with particular functional traits; species identity matters. }\end{array}$ \\
\hline 10 & $\begin{array}{l}\text { Ecosystem collapse can sometimes be positive by creating new opportunities, for example evolutionary diversification and } \\
\text { radiation, or by increasing provision of benefits to people. }\end{array}$ \\
\hline 11 & $\begin{array}{l}\text { Ecosystem recovery is dependent on intrinsic factors, namely interactions of organisms between each other and with the } \\
\text { physical environment. The rate or extent of recovery can be limited by intrinsic factors, and / or by extrinsic factors, such as } \\
\text { the disturbance regime and the extent of ecosystem degradation. }\end{array}$ \\
\hline 12 & Ecosystem recovery can take a long time, and always takes longer than collapse. \\
\hline
\end{tabular}

\section{Identify and Address Knowledge Gaps}

One of the most positive outcomes of the RLTS is the way that it stimulated research interest in threatened species, the results of which helped refine the assessment protocols through a process of iterative development (e.g., see [55]). Hopefully, the RLE and NCS will similarly lead to increased research interest in ecosystem collapse, and will employ the results of such research to improve how the assessments are conducted. It is very encouraging to note that the RLE intends to regularly update its application guidelines, conceptual framework and working definitions, and to implement a supporting research agenda [8]. Perhaps the most pressing need is to provide a stronger scientific basis for the thresholds associated with RLE criteria, as called for by Boitani et al. [21]. Bland et al. [6] highlight a number of additional research needs, including: (1) development and application of spatial, biotic and abiotic indicators of collapse, to capture its many dimensions; and (2) use of ecological models to diagnose mechanisms and pathways of ecosystem change, which would inform the selection of indicators.

Although a wide range of different modelling approaches have been used to explore the dynamics of ecosystems, none has so far been developed that explicitly addresses what is required by the RLE or related assessment approaches. Bland et al. [4] describe how ecological models can be used to support RLE assessments, specifically in relation to Criterion $\mathrm{E}$ (quantitative risk analysis). According to these authors, such models should be based on a sound understanding of ecosystem dynamics and function, and be supported by empirical 
data and inferences from similar ecosystems. Candidate modelling approaches listed by Bland et al. [4] include state-and-transition models, mass-balance models, bifurcation plots, models associated with network theory (e.g., Community Viability Analysis), dynamic Global Vegetation Models, dynamic species distribution and population models, spatial models (e.g., cellular automata) and general ecosystem models. However, none of these modelling approaches could be used to simulate multiple threatening processes and their potential interactions in a spatially explicit way, together with their relationships to the attributes of ecosystems referred to by the RLE criteria. New modelling approaches may therefore need to be developed to support implementation of the RLE, which might provide insights into different collapse mechanisms and trajectories, as envisaged by Bland et al. [6].

I briefly summarize here results of some recent research to illustrate how our understanding of ecosystem collapse is evolving, while also suggesting possible research priorities for the future. Each of these examples also has implications for how collapse risk is assessed.

- Rocha et al. [56] provide evidence of cascading regime shifts, some of which refer to examples of ecosystem collapse. Nearly half of the regime shifts considered showed some evidence of structural interdependence, suggesting that cascades might be widespread. In other words, collapse of one ecosystem might often lead to collapse of another to which it is connected, a risk that is not explicitly considered by the RLE or NCS. As the authors recognise, the study has a number of limitations, including biases in the selection of case studies, the small sample size and the fact that mechanisms were hypothesised and not necessarily tested empirically [56]. For example, it was assumed that the regime shifts were driven by feedback loops, whereas they might have been caused solely by changes in external drivers [25]. Other examples show that ecosystem collapse cascades can occur without any feedback mechanisms, for example if collapse of one ecosystem creates a driver of collapse for another [25]. For example, if a forest is clearfelled, or a river catchment degraded, increased soil erosion could destroy coastal ecosystems such as coral reefs. McCulloch et al. [57] provide an example of this process for the Australian Great Barrier Reef. Further research is needed to identify how widespread such linkages are, and the mechanisms involved.

- Cooper et al. [51] provided evidence showing that ecosystem transitions occur disproportionately faster in larger ecosystems. In other words, each additional unit area of an ecosystem provides a correspondingly smaller unit of time to collapse. This finding has clear implications for the definition of thresholds employed by the RLE, and suggests that the use of even intervals for threshold values may be inappropriate. The authors speculate that there may be a fundamental mechanism that links ecosystem size, structure and speed of collapse, although the nature of this remains unclear. Conversely, Hillebrand et al. [58] concluded that human-induced changes in ecosystems are typically characterised by gradual shifts rather than by threshold responses, based on an assessment of 36 meta-analyses. As this finding contradicts that of Cooper et al. [51], further research is required to determine whether or not ecosystem collapse trajectories typically display thresholds.

- Bergstrom et al. [23] describe an assessment of collapse risk in 19 Australian ecosystems, using an approach that differed from that of the RLE or NCS. Results provided evidence of local-scale collapse in every ecosystem type considered, although none had collapsed throughout their entire distribution. This highlights a key knowledge gap: the relationship between collapse of an ecosystem at local scales, which may be widespread, and collapse at regional or global scales [59]. The existence of interconnections between spatially isolated areas of a particular ecosystem type, for example via the climate system, raise the possibility of cumulative local-scale collapses leading to larger-scale system collapse. Such processes have been suggested for the forests of the Amazon basin, for example [60].

- Harris et al. [61] describe collapse of six Australian ecosystems owing to a combination of climatic 'pulse' disturbances at critical periods, together with the ongoing 'press' of 
continuous climate change. The authors highlight the need for a better mechanistic understanding of how sudden or extreme events can interact with press disturbances, such as climate change, to cause ecosystem collapse. Furthermore, climate change can interact with other types of disturbance to increase the severity and frequency of the disturbance regime, leading to the possibility of chronic disequilibrium of ecosystems [62]. This raises the question of whether the role of climate change in driving ecosystem collapse is adequately considered by current assessments of collapse risk.

- Newton [25] highlights the importance of understanding the mechanisms responsible for ecosystem recovery, recognising that collapse is often associated with a failure of these mechanisms. This aspect is currently neglected by assessments of collapse risk. It is possible, for example, that the recovery of one ecosystem might lead to the recovery of another to which it is connected, as a corollary of the phenomena described by Rocha et al. [56]. Other key knowledge gaps include the relative importance of intrinsic and extrinsic factors in limiting ecosystem recovery; existence of thresholds of degradation beyond which recovery is not possible; and the extent to which ecosystem recovery can occur in the presence of ongoing chronic disturbance, such as climate change [25].

\section{Share and Communicate Challenges}

In the context of the RLE, Keith et al. [8] highlight the need to learn from applications of the criteria to different ecosystem types and locations, to iteratively develop and improve the assessment process over time. This implies a need to share and communicate information about any challenges that are encountered, in an open and transparent way. Based on experience with the RLTS, these challenges are most likely to relate to lacking or uncertain data, and difficulties with interpreting the criteria and thresholds in specific situations, which can sometimes arise from confusion about how they should be applied $[55,63,64]$. Implementation of the RLE is still at an early stage, but some of the challenges that have been identified in ecosystem assessments conducted to date include:

- lack of information on ecosystems - in many countries there is very limited ecological information available about ecosystems, which is needed to apply the assessment criteria [65,66];

- lack of historic data-in the case of coral ecosystems in the Caribbean of Colombia, particular challenges were encountered in the use of reference values to determine historical trends; there was a lack of modelled or empirical data before 1994 in the study area [67];

- $\quad$ uncertain data-although satellite remote sensing data are widely used for mapping and assessing the condition of different ecosystems, there is considerable uncertainty about how to effectively utilise such data for collapse risk assessment [68];

- lack of indicators - estimating collapse risk can be challenging for ecosystems dominated by a small number of species, owing to the limited number of indicators that can be used to apply the RLE criteria [69];

- lack of information on stressors - there are limited or non-existent data on the spatial distribution or temporal change in their intensity of many stressors to ecosystems (e.g., deep sea mining, plastic pollution, offshore energy, aquaculture, noise pollution and oil spills in the case of marine ecosystems); information is also lacking on interactions between stressors and relationships with ecosystem condition, which may be nonlinear [70];

- limited data resolution - in an assessment of forest ecosystems in the Americas, problems of data resolution were encountered; the use of relatively broad classification units at the regional scale might have overlooked local trends; data for some indicators were only available at coarse resolution; and data for some threats (e.g., fire regimes) were lacking [13];

- limited applicability of criteria-assessment criteria developed for terrestrial ecosystems may be poorly applicable to other ecosystem types; for example estuarine ecosys- 
tems rarely change significantly in area and are typically small in extent, limiting the applicability of criteria based on geographic distribution [71];

- collapse thresholds unknown - in the case of mangrove ecosystems, data on some indicators are not currently available, and quantitative collapse thresholds-below which characteristic biota, ecological functions and/or processes are not supportedare often unknown; this has formed a bottleneck in the RLE assessment process [72];

- interconnections between ecosystems-different ecosystem types in a single area can have strong interconnections, and this connectivity should be explicitly considered in assessments of such ecosystems; for example in Queensland, expansion of a mangrove ecosystem is threatening saltmarsh, a process that would be missed if all coastal wetlands were assessed as a single entity; this highlights the benefit of conducting multi-ecosystem assessments especially where there is high ecological connectivity [73].

These examples illustrate how the challenges associated with ecosystem collapse assessments can usefully be communicated in the scientific literature; in some cases, these articles also suggested potential solutions to the problems that were identified. Clearly, those involved in conducting ecosystem collapse risk assessments in the future should be encouraged to share information in a similar way. There might also be value in capturing and consolidating these insights, to ensure that they inform the future development of the RLE. Future assessments might also usefully be supported by the development of analytical tools to facilitate application of criteria and thresholds using uncertain data, as occurred with the RLTS [74,75].

A second type of challenge relates to how the results of collapse risk assessments are used, specifically in relation to environmental policy. In their review of the impacts of the RLE on policy, Bland et al. [12] suggested that indices based on RLE assessments have high potential to inform global biodiversity monitoring and reporting, as has occurred with the RLTS. For example, RLE indices could inform monitoring towards the Aichi Targets of the Convention on Biological Diversity, and the United Nations Sustainable Development Goals, by "quantifying changes in risks over time" [12]. These ideas were explored further by Rowland et al. [15], who described such an index, namely the Red List Index of Ecosystems (RLIE), together with two associated indices focusing respectively on collapse risk owing to declines in distribution (Ecosystem Area Index, EAI) and degradation (Ecosystem Health Index, EHI). These are designed to complement the conceptually similar Red List Index for species (RLI). Some potential challenges in implementation of the RLIE were highlighted; for example, it was recommended that the indices are interpreted carefully, as the EHI and EAI may not always be completely independent; indices may be unreliable if insensitive variables are used; and the fact that data may often be limited or absent should be borne in mind [15]

Although mention is made of these potential limitations, neither Bland et al. [12] nor Rowland et al. [15] referred to a more fundamental conceptual problem that exists if the RLE is used to monitor and inform conservation policy. In the case of the RLTS, extinction of a species unequivocally represents an example of biodiversity loss. However, the same is not true for ecosystem collapse, as assessed by the RLE. This is because ecosystems that collapse differ from species that become extinct, in that they do not disappear altogether. Rather, they can transform into something else-namely another type of ecosystem. This could result in loss of some ecosystem characteristics. Conversely, in some situations, ecosystem collapse can result in an increase in species richness, in ecosystem function, or potentially in any other indicator of ecosystem condition [25]. This counterintuitive situation is attributable to the fact that transformed ecosystems can sometimes be of higher value, for either wildlife or people, than the ecosystems that they replace.

As illustration, consider an ecological restoration project that has established native forest on grassland, which had been maintained in that state for long time-scales by agricultural land use (e.g., the Carrifran Wildwood project in the UK; [76]). Such a restoration initiative can provide demonstrable benefits to biodiversity, ecosystem function and associ- 
ated services [77], yet would be classified as ecosystem collapse according to the RLE. Other examples include "novel ecosystems", namely those with assemblages of species or other characteristics that human activities have created [78]. These include agro-ecosystems, forest plantations and the novel assemblages of species that can form in response to climate change [78,79]. Creation of a novel ecosystem could be classified as ecosystem collapse, yet such ecosystems can sometimes be of significant value for biodiversity conservation [28], and they are increasingly featuring among conservation management goals [80-83].

It has been suggested previously that indicators based on the RLTS, such as the RLI, may have limited value as biodiversity indicators, owing to biases, uneven coverage and inaccuracies in available data, and a lack of correlation with threatening processes [84,85]. However, the problem with the RLEI is potentially far more significant: declining values will be interpreted as evidence of biodiversity loss, whereas the converse could be true. Consider the situation in a country such as China, where a number of large-scale ecological restoration initiatives have been implemented, resulting in both negative and positive environmental impacts [86]. Using the RLEI, it would be impossible to differentiate between those restoration actions that have benefitted biodiversity from those that have caused environmental damage, as both could be considered as ecosystem collapse. This suggests that great care will need to be taken when using indicators derived from the RLE, and the potential problems associated with them will need to be clearly communicated to the user community so that the results are not misinterpreted.

\section{Conclusions}

Development of the RLE and associated assessment processes has undoubtedly had a positive impact on global efforts towards biodiversity conservation. As noted by FerrerParis et al. [13], the development of a systematic risk assessment protocol for ecosystems, which incorporates uncertainties in underlying data, represents a significant advance over previous assessment approaches. Put simply, the RLE has helped place ecosystems more firmly on the global conservation map. In 2005, following a major collaborative international effort, the Millennium Ecosystem Assessment attempted to provide a comprehensive statement about the status of the world's ecosystems [87]. Yet it is notable what the MEA did not produce: neither a global typology of the world's ecosystems, nor a comprehensive assessment of their conservation status. Owing to development of the RLE and associated approaches, these are now within reach.

However, during its early development, concerns were raised about the scientific basis of the RLE [21]. These concerns have not been fully addressed, and other issues have subsequently been identified. Here I suggest that these problems could potentially be addressed by:

(i) changing the description of the endpoint to "completely transformed" instead of "collapsed", or changing the RLE definition of collapse to explicitly limit it to ecosystem decline that is abrupt;

(ii) developing a general ecological theory that explicitly addresses ecosystem collapse;

(iii) using ecological theory to refine the assessment thresholds associated with the different criteria;

(iv) developing ecological models that enable ecosystem collapse to be forecast, to support implementation of the RLE and to provide insights into underlying collapse mechanisms;

(v) recognising the linkages between ecosystem collapse and ecological recovery, and reflecting these in the RLE criteria;

(vi) revising the RLE criteria and thresholds in the light of new research, for example into spatial linkages between ecosystems, ecosystem collapse cascades, the shape of collapse trajectories, cross-scale linkages, the impacts of climate change, underlying collapse mechanisms and relationship to recovery processes;

(vii) sharing and communicating information about challenges that are encountered when implementing the RLE, and revising the assessment protocol in the light of this evidence; 
(viii) either ceasing promotion of the use of indicators based on the RLE, or communicating the problems associated with these indicators to potential users, to prevent results from being mis-interpreted or mis-used.

Some of these problems have already been recognised by the researchers responsible for developing the RLE. For example, Keith et al. [8] recognised that collapse can lead to the creation of novel ecosystems, which could sometimes be considered desirable. However, this realisation has not informed the development of indicators based on the RLE, which could consequently provide misleading information. Specifically, such indicators should not be interpreted as unequivocal evidence for biodiversity loss.

While recognising that the RLE has limitations, Keith et al. [8] suggest that it should be judged by whether these limitations are outweighed by its benefits, and whether it improves conservation outcomes. This is surely correct. However, the societal value of the RLE ultimately depends on its scientific credibility, and if that is being questioned, then steps need to be taken to address these criticisms. Any scientific weaknesses could be exploited by those who oppose recommendations for conservation action that are based upon it. Keith et al. [8] are also right to state that the way in which results of the RLE are used to inform choice of conservation priorities will depend upon the relative values of different outcomes. For example, a collapsed ecosystem (such as a novel ecosystem) could be included among conservation management goals, if its biodiversity value were judged to be relatively high [28]. However, there is an implicit value that is embedded within the RLE: namely that ecosystems at higher risk of collapse are in some way deserving of greater conservation attention than those at lower risk. This may not always be the case. Consequently, use of the RLE could lead to outcomes that are perverse. For example, rewilding is attracting increasing interest as a conservation approach; in Europe it is typically achieved through the abandonment of agricultural land [88-90]. Such rewilding can deliver substantial benefits for both wildlife and people, but according to the RLE, it could constitute a form of ecosystem collapse. Those campaigning against rewilding could therefore use the results of the RLE to strengthen their position.

Perhaps the most pressing issue relating to the RLE is not the design and implementation of the assessment process itself, but the deficiencies in scientific understanding that it has highlighted. This is most evident in relation to climate change. Keith et al. [8] suggest that the RLE provides an adequate framework for assessing risks of ecosystem collapse caused by climate change, while noting that the creation of novel ecosystems driven by no-analogue climates remains a significant challenge. Yet the ability to accurately estimate such risks requires a thorough scientific understanding of how ecosystems respond to climate change, and the underlying mechanisms involved. We know that climate change has the capacity to profoundly transform all of the world's ecosystem in coming decades, and we also know that climate change can potentially interact with all of the other threatening processes affecting ecosystems, although the precise mechanisms are not well understood [25,91]. Evidence indicates that many ecosystem types can alter rapidly in response to climate change, but for many ecosystem types, we currently lack sufficient understanding to forecast accurately when and where this might happen [92,93]. Without this understanding, the RLE might fail to identify ecosystems that are at high risk of sudden collapse. Hopefully, future development and implementation of the RLE will stimulate the further research that is required to provide a detailed understanding of the causes of ecosystem collapse, especially in response to climate change.

Funding: This research received no external funding.

Institutional Review Board Statement: Not applicable.

Informed Consent Statement: Not applicable.

Conflicts of Interest: The author declares no conflict of interest. 


\section{References}

1. Betts, J.; Young, R.P.; Hilton-Taylor, C.; Hoffmann, M.; Rodríguez, J.P.; Stuart, S.N.; Milner-Gulland, E. A framework for evaluating the impact of the IUCN Red List of threatened species. Conserv. Biol. 2020, 34, 632-643. [CrossRef]

2. BGCI. State of the World's Trees; Botanic Gardens Conservation International (BGCI): Richmond, UK, 2021.

3. Rodríguez, J.P.; Balch, J.K.; Rodríguez-Clark, K.M. Assessing extinction risk in the absence of species-level data: Quantitative criteria for terrestrial ecosystems. Biodivers. Conserv. 2007, 16, 183-209. [CrossRef]

4. Bland, L.M.; Keith, D.A.; Miller, R.M.; Murray, N.J.; Rodríguez, J.P. Guidelines for the Application of IUCN Red List of Ecosystems Categories and Criteria, version 1.1; International Union for the Conservation of Nature: Gland, Switzerland, 2017.

5. $\quad$ Bland, L.M.; Regan, T.J.; Dinh, M.N.; Ferrari, R.; Keith, D.A.; Lester, R.; Mouillot, D.; Murray, N.J.; Nguyen, H.A.; Nicholson, E. Using multiple lines of evidence to assess the risk of ecosystem collapse. Proc. R. Soc. B Biol. Sci. 2017, 284, 20170660. [CrossRef]

6. Bland, L.M.; Rowland, J.A.; Regan, T.J.; Keith, D.A.; Murray, N.J.; Lester, R.E.; Linn, M.; Rodríguez, J.P.; Nicholson, E. Developing a standardized definition of ecosystem collapse for risk assessment. Front. Ecol. Environ. 2018, 16, 29-36. [CrossRef]

7. Keith, D.A.; Rodríguez, J.P.; Rodríguez-Clark, K.M.; Aapala, K.; Alonso, A.; Asmussen, M.; Bachman, S.; Bassett, A.; Barrow, E.G.; Benson, J.S.; et al. Scientific foundations for an IUCN Red List of Ecosystems. PLoS ONE 2013, 8, 62111.

8. Keith, D.A.; Rodríguez, J.P.; Brooks, T.M.; Burgman, M.A.; Barrow, E.G.; Bland, L.; Comer, P.J.; Franklin, J.; Link, J.; McCarthy, M.A.; et al. The IUCN Red List of Ecosystems: Motivations, challenges, and applications. Conserv. Lett. 2015, 8, 214-226. [CrossRef]

9. Faber-Langendoen, D.; Nichols, J.; Master, L.; Snow, K.; Tomaino, A.; Bittman, R.; Hammerson, G.; Heidel, B.; Ramsay, L.; Teucher, A.; et al. NatureServe Conservation Status Assessments: Methodology for Assigning Ranks; NatureServe: Arlington, VA, USA, 2012.

10. Master, L.L.; Faber-Langendoen, D.; Bittman, R.; Hammerson, G.A.; Heidel, B.; Ramsay, L.; Snow, K.; Teucher, A.; Tomaino, A. NatureServe Conservation Status Assessments: Factors for Evaluating Species and Ecosystem Risk; NatureServe: Arlington, VA, USA, 2012.

11. NatureServe Statuses. NatureServe Explorer; NatureServe: Arlington, VA, USA, 2021; Available online: https://explorer. natureserve.org/ (accessed on 20 September 2021).

12. Bland, L.M.; Nicholson, E.; Miller, R.M.; Andrade, A.; Carré, A.; Etter, A.; Keith, D.A. Impacts of the IUCN Red List of Ecosystems on conservation policy and practice. Conserv. Lett. 2019, 12, e12666. [CrossRef]

13. Ferrer-Paris, J.R.; Zager, I.; Keith, D.A.; Oliveira-Miranda, M.A.; Rodríguez, J.P.; Josse, C.; Barrow, E. An ecosystem risk assessment of temperate and tropical forests of the Americas with an outlook on future conservation strategies. Conserv. Lett. 2019, 12 , e12623. [CrossRef]

14. Etter, A.; Andrade, A.; Nelson, C.R.; Cortés, J.; Saavedra, K. Assessing restoration priorities for high-risk ecosystems: An application of the IUCN Red List of Ecosystems. Land Use Policy 2020, 99, 104874. [CrossRef]

15. Rowland, J.A.; Bland, L.M.; Keith, D.A.; Juffe-Bignoli, D.; Burgman, M.A.; Etter, A.; Nicholson, E. Ecosystem indices to support global biodiversity conservation. Conserv. Lett. 2020, 13, e12680. [CrossRef]

16. Secretariat of the Convention on Biological Diversity. Global Biodiversity Outlook 5; Secretariat of the Convention on Biological Diversity: Montreal, QC, Canada, 2020.

17. UN Environment. Global Environment Outlook-GEO-6: Healthy Planet, Healthy People; UN Environment: Nairobi, Kenya, 2019.

18. Alaniz, A.J.; Perez-Quezada, J.F.; Galleguillos, M.; Vásquez, A.E.; Keith, D.A. Operationalizing the IUCN Red List of Ecosystems in public policy. Conserv. Lett. 2019, 12, e12665. [CrossRef]

19. Faber-Langendoen, D.; Lemly, J.; Nichols, W.; Rocchio, J.; Walz, K.; Smyth, R. Development and evaluation of NatureServe's multi-metric ecological integrity assessment method for wetland ecosystems. Ecol. Indic. 2019, 104, 764-775. [CrossRef]

20. Regan, T.J.; Master, L.L.; Hammerson, G.A. Capturing expert knowledge for threatened species assessments: A case study using NatureServe conservation status ranks. Acta Oecol. 2004, 26, 95-107. [CrossRef]

21. Boitani, L.; Mace, G.M.; Rondinini, C. Challenging the scientific foundations for an IUCN Red List of ecosystems. Conserv. Lett. 2015, 8, 125-131. [CrossRef]

22. IUCN. IUCN Global Ecosystem Typology. Available online: https:/ /iucnrle.org/about-rle/ongoing-initiatives/global-ecosystemtypology / (accessed on 21 September 2021).

23. Bergstrom, D.M.; Wienecke, B.C.; van den Hoff, J.; Hughes, L.; Lindenmayer, D.B.; Ainsworth, T.D.; Baker, C.M.; Bland, L.; Bowman, D.M.J.S.; Brooks, S.T.; et al. Combating ecosystem collapse from the tropics to the Antarctic. Glob. Chang. Biol. 2021, 27, 1692-1703. [CrossRef]

24. MacDougall, A.S.; McCann, K.S.; Gellner, G.; Turkington, R. Diversity loss with persistent human disturbance increases vulnerability to ecosystem collapse. Nature 2013, 494, 86-89. [CrossRef]

25. Newton, A.C. Ecosystem Collapse and Recovery; Cambridge University Press: Cambridge, UK, 2021.

26. Sato, C.F.; Lindenmayer, D.B. Meeting the global ecosystem collapse challenge. Conserv. Lett. 2017, 11, 12348. [CrossRef]

27. Dasgupta, P. The Economics of Biodiversity: The Dasgupta Review; HM Treasury: London, UK, 2021.

28. Newton, A.C.; Britton, R.; Davies, K.; Diaz, A.; Franklin, D.J.; Herbert, R.; Hill, R.A.; Hodder, K.; Jones, G.; Korstjens, A.H.; et al. Operationalising the concept of ecosystem collapse for conservation practice. Biol. Conserv. 2021, 264, 109366. [CrossRef]

29. Rodríguez, J.P.; Rodríguez-Clark, K.M.; Baillie, J.E.; Ash, N.; Benson, J.; Boucher, T.; Zamin, T. Establishing IUCN Red List Criteria for Threatened Ecosystems. Conserv. Biol. 2011, 25, 21-29. [CrossRef]

30. Altheide, D.L.; Michalowski, R.S. Fear in the news. A discourse of control. Sociol. Q. 1999, 40, 475-503. [CrossRef] 
31. Weinstein, N.; Rogerson, M.; Moreton, J.; Balmford, A.; Bradbury, R.B. Conserving nature out of fear or knowledge? Using threatening versus connecting messages to generate support for environmental causes. J. Nat. Conserv. 2015, 26, 49-55. [CrossRef]

32. Mace, G.M.; Lande, R. Assessing extinction threats: Toward a reevaluation of IUCN Threatened Species Categories. Conserv. Biol. 1991, 5, 148-157. [CrossRef]

33. Kolasa, J. Theory Makes Ecology Evolve. In The Theory of Ecology; Scheiner, S.M., Willig, M.R., Eds.; The University of Chicago Press: Chicago, IL, USA, 2011; pp. 21-49.

34. Marquet, P.A.; Allen, A.P.; Brown, J.H.; Dunne, J.A.; Enquist, B.J.; Gillooly, J.F.; West, G.B. On theory in ecology. BioScience 2014, 64, 701-710. [CrossRef]

35. Newton, A.C.; Echeverría, C. Analysis of Anthropogenic Impacts on Forest Biodiversity as a Contribution to Empirical Theory. In Forests and Global Change; Coomes, D.A., Burslem, D.F.R.P., Simonson, W.D., Eds.; BES Symposium Volume; Cambridge University Press: Cambridge, UK, 2014; pp. 417-446.

36. Peters, R.H. A Critique for Ecology; Cambridge University Press: Cambridge, UK, 1991.

37. Pickett, S.T.A.; Kolasa, J.; Jones, C.G. Ecological Understanding: The Nature of Theory and the Theory of Nature, 2nd ed.; Elsevier: Amsterdam, The Netherlands; Boston, MA, USA; Heidelberg, Germany; London, UK, 2007.

38. Leibold, M.A.; Holyoak, M.; Mouquet, N.; Amarasekare, P.; Chase, J.M.; Hoopes, M.F.; Holt, R.D.; Shurin, J.B.; Law, R.; Tilman, D.; et al. The metacommunity concept: A framework for multiscale community ecology. Ecol. Lett. 2004, 7, 601-613. [CrossRef]

39. Turner, M.G.; Gardner, R.H. Landscape Ecology in Theory and Practice; Springer: New York, NY, USA, 2015.

40. O'Neill, R.V.; Deangelis, D.L.; Waide, J.B.; Allen, T.F.H. A Hierarchical Concept of Ecosystems; Princeton University Press: Princeton, NJ, USA, 1986.

41. Norberg, J.; Cumming, G. Complexity Theory for a Sustainable Future; Columbia University Press: New York, NY, USA, 2008.

42. Andersen, T.; Carstensen, J.; Hernandez-Garcia, E.; Duarte, C.M. Ecological thresholds and regime shifts: Approaches to identification. Trends Ecol. Evol. 2009, 24, 49-57. [CrossRef]

43. Petraitis, P.S. Multiple Stable States in Natural Ecosystems; Oxford University Press: Oxford, UK, 2013.

44. Scheffer, M. Critical Transitions in Nature and Society; Princeton University Press: Princeton, NJ, USA, 2009.

45. Scheffer, M.; Carpenter, S.R. Catastrophic regime shifts in ecosystems: Linking theory to observation. Trends Ecol. Evol. 2003, 18, 648-656. [CrossRef]

46. Lindenmayer, D.; Messier, C.; Sato, C. Avoiding ecosystem collapse in managed forest ecosystems. Front. Ecol. Environ. 2016, 14, 561-568. [CrossRef]

47. Capon, S.J.; Lynch, A.J.J.; Bond, N.; Chessman, B.C.; Davis, J.; Davidson, N.; Mac Nally, R. Regime shifts, thresholds and multiple stable states in freshwater ecosystems; a critical appraisal of the evidence. Sci. Total Environ. 2015, 534, 122-130. [CrossRef]

48. Lloyd, J.; Veenendaal, E.M. Are fire mediated feedbacks burning out of control? Biogeosci. Discuss. 2016, 1-20. [CrossRef]

49. Dudgeon, S.R.; Aronson, R.B.; Bruno, J.F.; Precht, W.F. Phase shifts and stable states on coral reefs. Mar. Ecol. Prog. Ser. 2010, 413, 201-216. [CrossRef]

50. Möllmann, C.; Diekmann, R. Marine ecosystem regime shifts induced by climate and overfishing. Adv. Ecol. Res. 2012, 47, 303-347.

51. Cooper, G.S.; Willcock, S.; Dearing, J.A. Regime shifts occur disproportionately faster in larger ecosystems. Nat. Commun. 2020, 11, 1175. [CrossRef]

52. Ford, E.D. Scientific Method for Ecological Research; Cambridge University Press: Cambridge, UK, 2000.

53. Loreau, M. From Populations to Ecosystems: Theoretical Foundations for a New Ecological Synthesis; Princeton University Press: Princeton, NJ, USA, 2010.

54. McCann, K.S. The diversity-stability debate. Nature 2000, 405, 228-233. [CrossRef] [PubMed]

55. Joppa, L.; Butchart, S.; Hoffmann, M.; Bachman, S.; Akcakaya, R.; Moat, J.; Bohm, M.; Holland, R.; Newton, A.C.; Hughes, A.; et al. The impact of alternative metrics on estimating Extent of Occurrence for extinction risk assessment. Conserv. Biol. 2016, 30, 362-370. [CrossRef]

56. Rocha, J.C.; Peterson, G.; Bodin, Ö.; Levin, S. Cascading regime shifts within and across scales. Science 2018, 362, 1379-1383. [CrossRef]

57. McCulloch, M.; Fallon, S.; Wyndham, T.; Hendy, E.; Lough, J.; Barnes, D. Coral record of increased sediment flux to the inner Great Barrier Reef since European settlement. Nature 2003, 421, 727-730. [CrossRef] [PubMed]

58. Hillebrand, H.; Donohue, I.; Harpole, W.S.; Hodapp, D.; Kucera, M.; Lewandowska, A.M.; Merder, J.; Montoya, J.M.; Freund, J.A. Thresholds for ecological responses to global change do not emerge from empirical data. Nat. Ecol. Evol. 2020, 4, 1502-1509. [CrossRef] [PubMed]

59. Hughes, T.P.; Carpenter, S.; Rockström, J.; Scheffer, M.; Walker, B. Multiscale regime shifts and planetary boundaries. Trends Ecol. Evol. 2013, 28, 389-395. [CrossRef] [PubMed]

60. Malhi, Y.; Roberts, J.T.; Betts, R.A.; Killeen, T.J.; Li, W.; Nobre, C.A. Climate change, deforestation, and the fate of the Amazon. Science 2008, 319, 169-172. [CrossRef]

61. Harris, R.M.B.; Beaumont, L.J.; Vance, T.R.; Tozer, C.R.; Remenyi, T.A.; Perkins-Kirkpatrick, S.E.; Mitchell, P.J.; Nicotra, A.B.; McGregor, S.; Andrew, N.R.; et al. Biological responses to the press and pulse of climate trends and extreme events. Nat. Clim. Chang. 2018, 8, 579-587. [CrossRef] 
62. McDowell, N.G.; Michaletz, S.T.; Bennett, K.E.; Solander, K.C.; Xu, C.; Maxwell, R.M.; Middleton, R.S. Predicting chronic climate-driven disturbances and their mitigation. Trends Ecol. Evol. 2018, 33, 15-27. [CrossRef]

63. Akçakaya, H.R.; Ferson, S.; Burgman, M.A.; Keith, D.A.; Mace, G.M.; Todd, C.R. Making consistent IUCN classifications under uncertainty. Conserv. Biol. 2000, 14, 1001-1013. [CrossRef]

64. Gaston, K.J.; Fuller, R.A. The sizes of species' geographic ranges. J. Appl. Ecol. 2009, 46, e12623. [CrossRef]

65. Alaniz, A.J.; Galleguillos, M.; Perez-Quezada, J.F. Assessment of quality of input data used to classify ecosystems according to the IUCN Red List methodology: The case of the central Chile hotspot. Biol. Conserv. 2016, 204, 378-385. [CrossRef]

66. Chen, G.; Wang, X.; Ma, K. Red list of China's forest ecosystems: A conservation assessment and protected area gap analysis. Biol. Conserv. 2020, 248, 108636. [CrossRef]

67. Uribe, E.S.; Luna-Acosta, A.; Etter, A. Red List of Ecosystems: Risk assessment of coral ecosystems in the Colombian Caribbean. Ocean. Coast. Manag. 2021, 199, 105416. [CrossRef]

68. Murray, N.J.; Keith, D.A.; Bland, L.M.; Ferrari, R.; Lyons, M.B.; Lucas, R.; Nicholson, E. The role of satellite remote sensing in structured ecosystem risk assessments. Sci. Total Environ. 2018, 619, 249-257. [CrossRef]

69. Marshall, A.; Schulte to Bühne, H.; Bland, L.; Pettorelli, N. Assessing ecosystem collapse risk in ecosystems dominated by foundation species: The case of fringe mangroves. Ecol. Indic. 2018, 91, 128-137. [CrossRef]

70. Halpern, B.S.; Frazier, M.; Afflerbach, J.; Lowndes, J.S.; Micheli, F.; O'Hara, C.; Selkoe, K.A. Recent pace of change in human impact on the world's ocean. Sci. Rep. 2019, 9, 11609. [CrossRef]

71. Mahoney, P.C.; Bishop, M.J. Assessing risk of estuarine ecosystem collapse. Ocean. Coast. Manag. 2017, 140, 46-58. [CrossRef]

72. Sievers, M.; Chowdhury, M.R.; Adame, M.F.; Bhadury, P.; Bhargava, R.; Buelow, C.; Friess, D.A.; Ghosh, A.; Hayes, M.A.; McClure, E.C.; et al. Indian Sundarbans mangrove forest considered endangered under Red List of Ecosystems, but there is cause for optimism. Biol. Conserv. 2020, 251, 108751. [CrossRef]

73. Sievers, M.; Pearson, R.M.; Turschwell, M.P.; Bishop, M.J.; Bland, L.; Brown, C.J.; Connolly, R.M. Integrating outcomes of IUCN red list of ecosystems assessments for connected coastal wetlands. Ecol. Indic. 2020, 116, 106489. [CrossRef]

74. Akçakaya, H.R.; Ferson, S. RAMAS Red List: Threatened Species Classification under Uncertainty. User Manual for Version 1.0; Applied Biomathematics: Setauket, NY, USA, 1999.

75. Newton, A.C. Use of a Bayesian Network for Red Listing under uncertainty. Environ. Model. Softw. 2010, 25, 15-23. [CrossRef]

76. Ashmole, M.; Ashmole, P. The Carrifran Wildwood Story: Ecological Restoration from the Grass Roots; Borders Forest Trust: Jedburgh, UK, 2009.

77. Adair, S. Carrifran: Ecological restoration in the Southern Uplands: New native woodland and vegetation succession in the Moffat Hills. Scott. For. 2016, 70, 30-40.

78. Barnosky, A.D.; Hadly, E.A.; Gonzalez, P.; Head, J.; Polly, P.D.; Lawing, A.M.; Eronen, J.T.; Ackerly, D.D.; Alex, K.; Biber, E.; et al. Merging paleobiology with conservation biology to guide the future of terrestrial ecosystems. Science 2017, 355, 6325. [CrossRef]

79. Keith, S.A.; Newton, A.C.; Herbert, R.J.H.; Morecroft, M.D.; Bealey, C.E. Non-analogous community formation in response to climate change. J. Nat. Conserv. 2009, 17, 228-235. [CrossRef]

80. Higgs, E.S.; Harris, J.A.; Heger, T.; Hobbs, R.J.; Murphy, S.D.; Suding, K.N. Keep ecological restoration open and flexible. Nat. Ecol. Evol. 2018, 2, 580. [CrossRef]

81. Higgs, E.; Harris, J.; Murphy, S.; Bowers, K.; Hobbs, R.; Jenkins, W.; Kidwell, J.; Lopoukhine, N.; Sollereder, B.; Suding, K.; et al. On principles and standards in ecological restoration. Restor. Ecol. 2018, 26, 399-403. [CrossRef]

82. Hobbs, R.J.; Arico, S.; Aronson, J.; Baron, J.S.; Bridgewater, P.; Cramer, V.A.; Zobel, M. Novel ecosystems: Theoretical and management aspects of the new ecological world order. Glob. Ecol. Biogeogr. 2006, 15, 1-7. [CrossRef]

83. Hobbs, R.J.; Higgs, E.; Harris, J.A. Novel ecosystems: Implications for conservation and restoration. Trends Ecol. Evol. 2009, 24, 599-605. [CrossRef]

84. Newton, A.C. Implications of Goodhart's Law for monitoring global biodiversity loss. Conserv. Lett. 2011, 4, 264-268. [CrossRef]

85. Possingham, H.P.; Andelman, S.J.; Burgman, M.A.; Medellin, R.A.; Master, L.L.; Keith, D.A. Limits to the use of threatened species lists. Trends Ecol. Evol. 2002, 17, 503-505. [CrossRef]

86. Cao, S.; Xia, C.; Suo, X.; Wei, Z. A framework for calculating the net benefits of ecological restoration programs in China. Ecosyst. Serv. 2021, 50, 101325. [CrossRef]

87. Hassan, R.; Scholes, R.; Ash, N. (Eds.) Ecosystems and Human Well-Being: Current State and Trends; Millennium Ecosystem Assessment Volume 1; Island Press: Washington, WA, USA, 2005.

88. Navarro, L.M.; Pereira, H.M. Rewilding abandoned landscapes in Europe. Ecosystems 2012, 15, 900-912. [CrossRef]

89. Loth, A.F.; Newton, A.C. Rewilding as a restoration strategy for lowland agricultural landscapes: Stakeholder-assisted multicriteria analysis in Dorset, UK. J. Nat. Conserv. 2018, 46, 110-120. [CrossRef]

90. Sandom, C.J.; Dempsey, B.; Bullock, D.; Ely, A.; Jepson, P.; Jimenez-Wisler, S.; Newton, A.; Pettorelli, N.; Senior, R.A. Rewilding in the English uplands: Policy and practice. J. Appl. Ecol. 2019, 56, 266-273. [CrossRef]

91. França, F.M.; Benkwitt, C.E.; Peralta, G.; Robinson, J.P.; Graham, N.A.; Tylianakis, J.M.; Barlow, J. Climatic and local stressor interactions threaten tropical forests and coral reefs. Philos. Trans. R. Soc. B Biol. Sci. 2020, 375, 20190116. [CrossRef] [PubMed] 
92. Jennings, M.D.; Harris, G.M. Climate change and ecosystem composition across large landscapes. Landsc. Ecol. 2017, 32, 195-207. [CrossRef]

93. Turner, M.G.; Calder, W.J.; Cumming, G.S.; Hughes, T.P.; Jentsch, A.; LaDeau, S.L.; Carpenter, S.R. Climate change, ecosystems and abrupt change: Science priorities. Philos. Trans. R. Soc. B Biol. Sci. 2020, 375, 20190105. [CrossRef] [PubMed] 